\title{
RANCANG BANGUN ARSITEKTUR JARINGAN KOMPUTER TEKNOLOGI METROPOLITAN AREA NETWORK (MAN) DENGAN MENGGUNAKAN METODE NETWORK DEVELOPMENT LIFE CYCLE (NDLC)
}

(Studi Kasus : Universitas Majalengka)

\author{
Harun Sujadi $^{1)}$, Aqis Mutaqin ${ }^{2)}$ \\ Program Studi Teknik Informatika, Fakultas Teknik, Universitas Majalengak ${ }^{1)}$ \\ Email: harunsujadi@gmail.com \\ Program Studi Teknik Informatika, Fakultas Teknik, Universitas Majalengak ${ }^{2)}$ \\ Email: agismutaqin04@gmail.com
}

\begin{abstract}
Majalengka University is a prominent campus located in Majalengka District of West Java Province. Majalengka University, have 8 faculty and 22 Programs, namely Faculty of Social and Political Sciences, Teacher and Education Science, Economics, Agriculture, Islam Religion, Engineering, Law, and Primary and Secondary Education.The existing computer network at Majalengka University currently uses Local Area Network (LAN) with is BUS topology. The problem is currently being experienced is still unclear of existing network architecture and there is often a failure in sending data and information through computer network that exist today. Because it has not been integrated wireless network that is made in all rooms that have been installed. System development method used is Network Development Life Cycle (NDLC) where the stages are as follows: Analysis, Design, Simulation Prototyping, Implementation, Monitoring, and Management.
\end{abstract}

Kata Kunci : Network Architecture, Metropolitan Area Network (MAN), Network Development Life Cycle (NDLC)

\section{PENDAHULUAN}

\subsection{Latar Belakang}

Di jaman modern ini peningkatan penggunaan perkembangan jaringan komputer berkembang semakin pesat. Banyak organisasi maupun kantor yang memanfaatkan jaringan komputer sebagai sarana dalam mengirimkan data. Data dan informasi merupakan hal penting yang harus diperhatikan, karena jika data dan informasi tersebut hilang (tidak terkirimkan), terkena virus internet akan sangat fatal, membuat data dan informasi tersebut tak berharga lagi. Pengiriman data bisa dikatakan baik jika koneksi jaringan komputernya berfungi dengan baik, dan tidak ada hambatan apapun. Karena koneksi jaringan merupakan hal yang mendasar dalam jaringan yang akan kita gunakan baik menggunakan jaringan Local Area Network (LAN), Metropolitan Area Network (MAN), dan Wide Area Network (WAN).

Jaringan merupakan kombinasi hardware, software, dan pengkabelan (cabling), yang secara bersama-sama memungkinkan berbagai peranti komputasi untuk berkomunikasi satu sama lain. Sedangkan jaringan komputer merupakan kumpulan dari sejumlah perangkat berupa komputer, hub, switch, router, atau perangkat jaringan lainnya yang terhubung dengan menggunakan media komunikasi tertentu.

Jaringan komputer merupakan hal yang penting terutama untuk mencari kerusakan jaringan secara cepat, dan mudah. Salah satu cara untuk mengatasi masalah di atas seorang administrator jaringan memerlukan aplikasi Network Monitoring System untuk simulasi yang dapat menggambarkan arsitektur dari jaringan komputer pada sistem jaringan yang digunakan. Salah satu software yang dapat gunakan yaitu cisco packec tracer, karena dapat mensimulasikan data mengenai jaringan, dapat memeriksa jaringan komputer apabila terjadi masalah dalam interkoneksi jaringan.

Universitas Majalengka merupakan kampus yang terkemuka yang terdapat di kabupaten Majalengka Provinsi Jawa Barat. Di Universitas Majalengka terdapat 8 fakultas dan 22 prodi yaitu Fakultas Ilmu Sosial dan Ilmu Politik, Keguruan dan Ilmu Pendidikan, Ekonomi, Pertanian, Agama Islam,Teknik, Hukum, dan Pendidikan Dasar dan Menengah.

Jaringan komputer yang ada di Universitas Majalengka saat ini menggunakan jaringan Local Area Network (LAN) dengan topologi yang digunakan adalah topologi BUS. Masalah jaringan 
komputer yang sekarang sedang dialami masih belum jelas arsitektur jaringan yang ada dan sering terjadi kegagalan dalam mengirimkan suatu data dan informasi melalui jaringan komputer yang ada saat ini. Karena belum terintergrasi jaringan wireless yang dibuat di semua ruangan yang telah dipasang.

Berdasarkan masalah tersebut, Maka penulis tertarik untuk melakukan penelitian. Sehingga dengan adanya arsitektur jaringan yang baru diharapkan dapat bisa bekerja dengan baik atau maksimal. Adapun masksud dari latar belakang diatas, maka penulis merumuskan masalah dalam penelitian ini adalah sebagai berikut :

1. Bagaimana membuat perancangan arsitektur jaringan?

2. Bagaimana cara penerapan arsitektur jaringan komputer?

3. Bagaimana proses pembuatan Blue Print jaringan di Universita Majalengka ?

Tujuan dan manfaat dari penelitian ini adalah dapat menggambarkan arsitektur jaringan di Universitas Majalengka dengan jelas, dan dapat mengetagui Blue Print jaringan di Universitas Majalengka.

\subsection{Kajian Literatur}

Rancang bangun merupakan serangkaian prosedur untuk menerjemahkan hasil analisa dari sebuah sistem kedalam bahasa pemrograman untuk mendeskripsikan dengan detail bagaimana komponen-komponen sistem diimplementasikan (Pressman R, 2002).

Arsitektur Jaringan dapat diartikan sebagai rancangan arus komunikasi media elektronik. Arsitektur jaringan merupakan sebuah himpunan layer (lapisan) dan protocol. Dimana layer bertujuan memberi layanan ke layer yang ada diatasnya (Fenorita, 2011).

(Siddiq Leksono, 2012) Sistem komunikasi membutuhkan medium sebagai pembawa sinyal (carrier). Sistem transmisi sinyal bisa berupa kabel, GEM (RF), dan Cahaya. Untuk dapat menyampaikan data, sistem komunikasi juga membutuhkan aturan (rule protocol). Sistem komunikasi adalah sebuah sistem kompleks yang dibangun dari medium transmisi, carrier, dan protocol.

Pengertian TCP/IP adalah sebuah perangkat lunak jaringan komputer yang terdapat dalam satu sistem dan memungkinkan komputer satu dengan komputer lain dapat mentransfer data dalam satu grup network atau jaringan. TCP singkatan dari Transmission Control Protocol dan IP singkatan dari Internet Protocol. TCP/IP menjadi satu nama karena fungsinya selalu bergandengan satu sama lain dalam komunikasi data (Hardiyanto Nugroho, 2013).

Packet Tracer adalah simulator alat-alat jaringan Cisco yang sering digunakan sebagai media pembelajaran dan pelatihan, dan juga dalam bidang penelitian simulasi jaringan komputer. Program ini dibuat oleh Cisco Systems dan disediakan gratis untuk fakultas, siswa dan alumni yang telah berpartisipasi di Cisco Networking Academy. Tujuan utama Packet Tracer adalah untuk menyediakan alat bagi siswa dan pengajar agar dapat memahami prinsip jaringan komputer dan juga membangun skill di bidang alat-alat jaringan Cisco (Gunawan Dwi, 2015).

ISSN 2355-1119, Arip Solehudin, dengan Judul Implementasi Arsitektur Jaringan Dan Penerapan Limiting Upload / Download File Extensions Menggunakan Mikrotik Router Di Laboratorium Komputer Unsika, Menggunakan metode Network Development Life Cycle (NDLC), Dan hasil penelitian yang sudah dilakukan adalah dengan menerapkan manajemen bandwith menggunakan ClearOS dapat membatasi akses internet saat praktikum di laboratorium komputer UNSIKA selain praktikum yang menggunakan fasilitas internet, dan sebagai manajemen user hotspot antara lain pemberian maksimal upload/download, username dan password dapat membatasi akses internet melalui hotspot di laboratorium komputer UNSIKA.

ISSN 2302-3805, Harun Sujadi dengan Judul Analisis Dan Perancangan Arsitektur Sistem Informasi Rumah Sakit Menggunakan Smart Card Berbasis Cloud Computing (Setudi Kasus RSUD Kabupaten Majalengka) Menggunakan Metode Framework Togaf, dan hasil penelitian Dengan menggunakan metodologi TOGAF sebagai kerangka yang digunakan dalam perencanaan arsitektur sistem informasi RSUD Cideres dan RSUD Majalengka, menghasilkan analisis proses bisnis yang terdiri dari rawat inap, rawat jalan, IGD, apotek dan rekam medis yang sesuai dengan visi dan misi perusahaan dan dapat dirancang di perusahaan. 


\section{METODOLOGI PENELITIAN}

\subsection{Metode pengembangan sistem}

Metode pengembangan sistem yang digunakan adalah metode Network Development Life Cyle (NDLC). Adapun tahapan dari metode NDLC adalah sebagai berikut : Analysis, Design, Simulation Prototype, Implementation Monitoring dan Management.

\subsection{Tahapan penelitian}

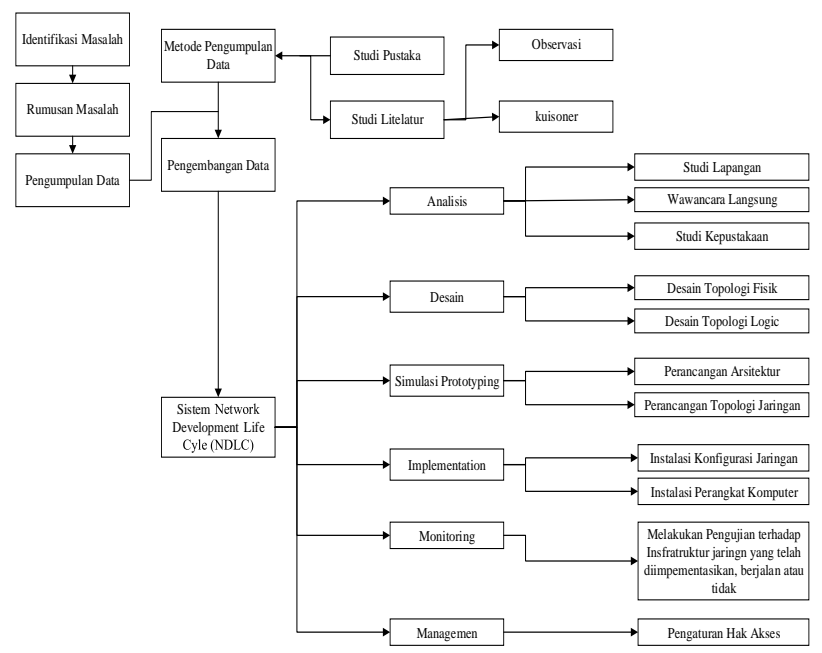

Gambar 1. Tahapan Penelitian

Keterangan dari gambar diatas adalah sebagai berikut :

1. Identifikasi Masalah, yaitu tahapan peneliti mengidentifikasi masalah-masalah apa yang akan di rumuskan dan pekerjaan apa yang akan dilakukan;

2. Perumusan Masalah, yaitu tahapan peneliti merumuskan masalah yang telah di identifikasi;

3. Pengumpulan Data, Metode pengumpulan data yang digunakan adalah studi pustaka, studi lapangan, dan studi literatur. Yaitu tahapan dimana peneliti mengumpulkan data-data yang telah didapat setelah melakukan observasi, wawancara, dan kuisioner;

4. Metode Pengembangan Sistem, Metode pengembangan sistem yang digunakan adalah metode Network Development Life Cyle (NDLC). NDLC adalah salah satu metode yang dilakukan dalam pengembangan metode dalam jaringan. Dimana NDLC memiliki enam (6) tahapan, tahapan-tahapan yang dimaksud adalah sebagai berikut :

a. Analysis, analisis adalah tahapan pertama yang dilakukan peneliti diantaranya analisa permasalahan, analisa use, dan analisa topologi jaringan yang ada di Universitas Majalengka;

b. Design, desain adalah tahapan kedua yang peneliti lakukan, dimana dalam tahapan desain ini akan dibuat penggambaran arsitektur, skema jaringan yang sedang berjalan, dan skema jaringan yang diusulkan yang ada di Universitas Majalengka;

c. Simulation Prototyping, adalah tahapan ketiga yang peneliti lakukan, dimana pada tahapan simulasi ini akan membangun prototipe sistem di Universitas Majalengka dari data yang telah didapat pada tahapan sebelumnya dengan menggunakan software cisco packet tracert sebagain replika dari sistem yang akan dijalankan;

d. Implementation, adalah tahapan keempat yang peneliti lakukan, dimana pada tahapan ini akan dilakukan spesifikasi rancangan di Universitas Majalengka yang akan dijalankan meliputi instalasi konfigurasi jaringan, instalasi jaringan perangkat keras (hadware);

e. Monitoring, adalah tahapan kelima yang peneliti lakukan, dimana pada tahapan monitoring ini dilakukan pengujian terhadap infrastruktur jaringan yang telah diterapkan/diimplementasikan di Universitas Majalengka, berjalan atau tidak;

f. Management, adalah tahapan keenam yang peneliti lakukan, dimana pada tahapan managemen ini mengatur masalah policy kebijakan agar sistem yang sudah dibangun dapat terjaga.

\section{HASIL PENELITIAN DAN PEMBAHASAN}

Pada Arsitektur yang sedang berjalan ini di gambarkan pada kampus 1 terdapat gedung 1 , bank Bjb, Server. Dikampus 2 terdapat gedung 2. Yang digambarkan pada gambar 2

\section{Computer Science | Industrial Engineering | Mechanic Engineering | Civil Engineering}




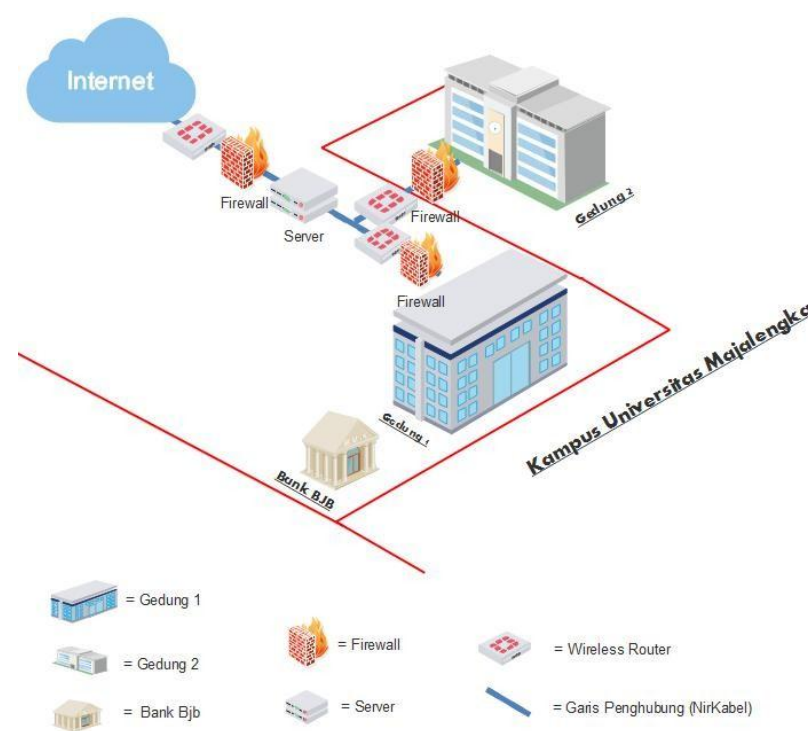

Gambar 2. Denah Universitas Majalengka

Pada Arsitektur dan denah yang akan diajukan ini di gambarkan pada kampus 1 dan Dikampus 2 terdapat gedung 2. Yang digambarkan pada gambar $3 \& 4$.

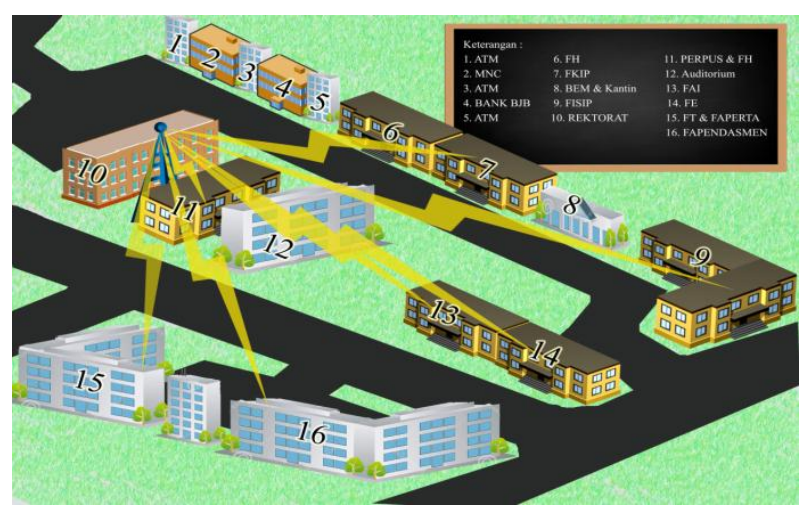

Gambar 3. Denah Universitas Majalengak

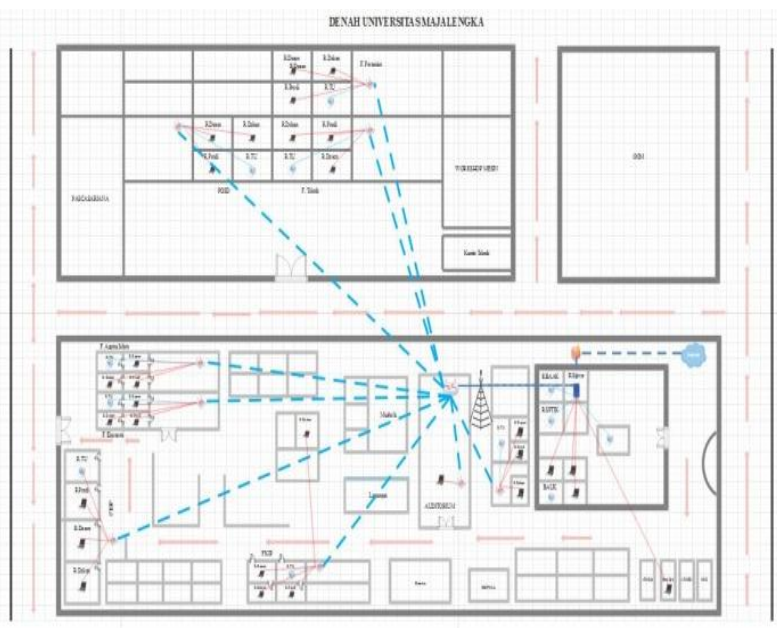

Gambar 4. Denah Universitas Majalengka

Perancangan arsitektur ini menjelaskan beberapa Fakultas atau Tata Usaha (TU) yang ada di universitas majalengka Sebagai berikut :

1. Rektorat

2. Auditorium

3. Fakultas Hukum

4. Fakultas Keguruan dan Ilmu Pendidikan

5. Fakultas Sosial dan Ilmu Politik

6. Fakultas Agama Islam

7. Fakultas Ekonomi

8. Fakultas Teknik

9. Fakultas Pendidikan Dasar Menengah

10. Pascasarjana

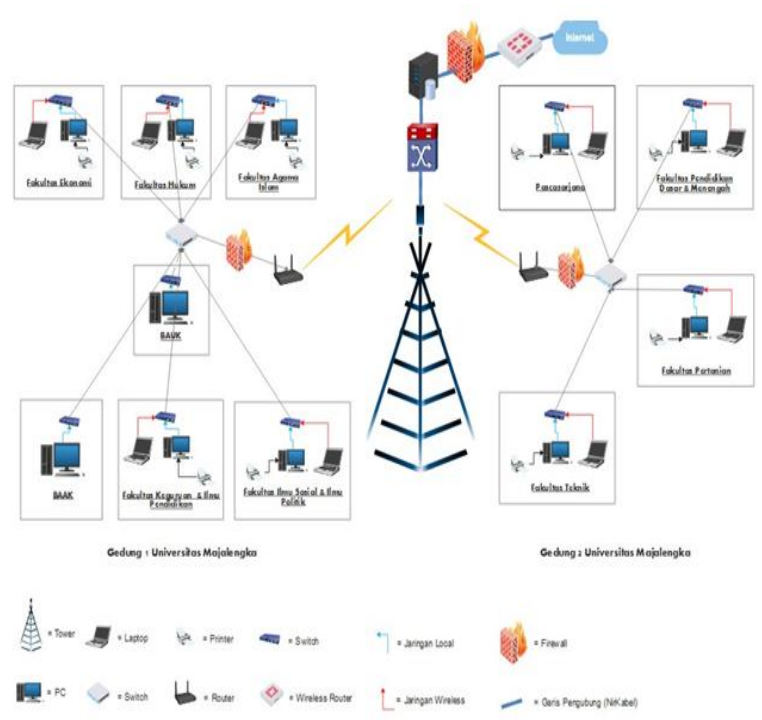

Gambar 5. Arsitektur Jaringan Universitas Majalengka 


\section{KESIMPULAN}

\subsection{Kesimpulan}

Dari hasil penelitian yang dilakukan di Universitas Majalengka tentang Rancang Bangun Jaringan menggunakan metode Network Development Life Cyle (NDLC), maka kesimpulan yang dapat di ambil di antaranya :

1. Dengan bantuan tools E-Draw, dapat merancang Arsitektur jaringan komputer di Universitas Majalengka, dengan rincian 8 Fakultas, 1 Pascasarjana setelah melakukan pengamatan langsung di lapangan;

2. Dengan bantuan tools Cisco tracer, dapat menggambarkan jaringan antar komputer lainnya, sehingga pada saat penerapan di lapangan diharapkan tidak ada kesalahan pemasangan perangkat jaringan;

3. Dengan adanya penelitian ini, penulis dapat membuat blue print denah kampus Universitas Majalengka.

\subsection{Saran}

Dalam penelitian yang sudah dilakukan yang berjudul "Rancang Bangun Arsitektur Jaringan Komputer Teknologi Metropolitan Area Network (MAN) Dengan Menggunakan Metode Network Development Life Cycle (NDLC), Masih banyak kekurangan yang harus diperbaiki. Untuk mengembangkan Arsitektur yang telah dibuat penulis menyarankan :

1. Dalam penggambaran Arsitektur sebaiknya menggunakan simbol yang jelas dan mudah dipahami;

2. Dalam penggambaran Denah Universitas Majalengka sebaiknya digambarkan secara detail, karena pada penelitian ini hanya perwakilan dari setiap Fakultas dan TU yang digambarkan;

\section{REFERENSI}

Arip Solehudin, "Implementasi Arsitektur Jaringan Dan Penerapan Limiting Upload/Download File Extensions Menggunakan Mikrotik Router Di Laboratorium Komputer Unsika”, Jurnal Ilmiah, Volume 2, Nomor 6, Agustus 2015.

Leksono, Siddiq. 2012. "Apa sih jaringan Kompter itu??".

http://siddiqleksono.wordpress.com/2012/10/ 15/apa-sih-jaringankomputer-itu/ diakses tanggal 11 maret 2012 pukul 07.20.

Nugroho, Hardiyanto. 2013. "Pengertian dan fungsi TCP/IP dalam jaringan komputer". http://hardiyanto-nugroho .blog. ugm. ac.id/ 2013 /02 / 27 / pengertian -dan-fungsi-tcpipdalam-jaringan-komputer/. Akses tanggal 18 Oktober 2017

Roger S. Pressman, 2002. Rekayasa Perangkat Lunak Pendekatan Praktisi (Buku Satu), ANDI Yogyakarta. Fenorita, Riza Mutiara. 2011. "Network Operating System" (online).http://rezimutiarafenorita.blogspot.co m/2011/07/nos-network-

operatingsystem.html diakses 31 Maret 2017 pukul 9.34)

Sujadi, Harun. Analisis Dan Perancangan Arsitektur Sistem Informasi Rumah Sakit Menggunakan Smart Card Berbasis Cloud Computing (Setudi Kasus RSUD Kabupaten Majalengka). SEMNASTEKNOMEDIA ONLINE, 2017, 5.1: 3-2-1. 